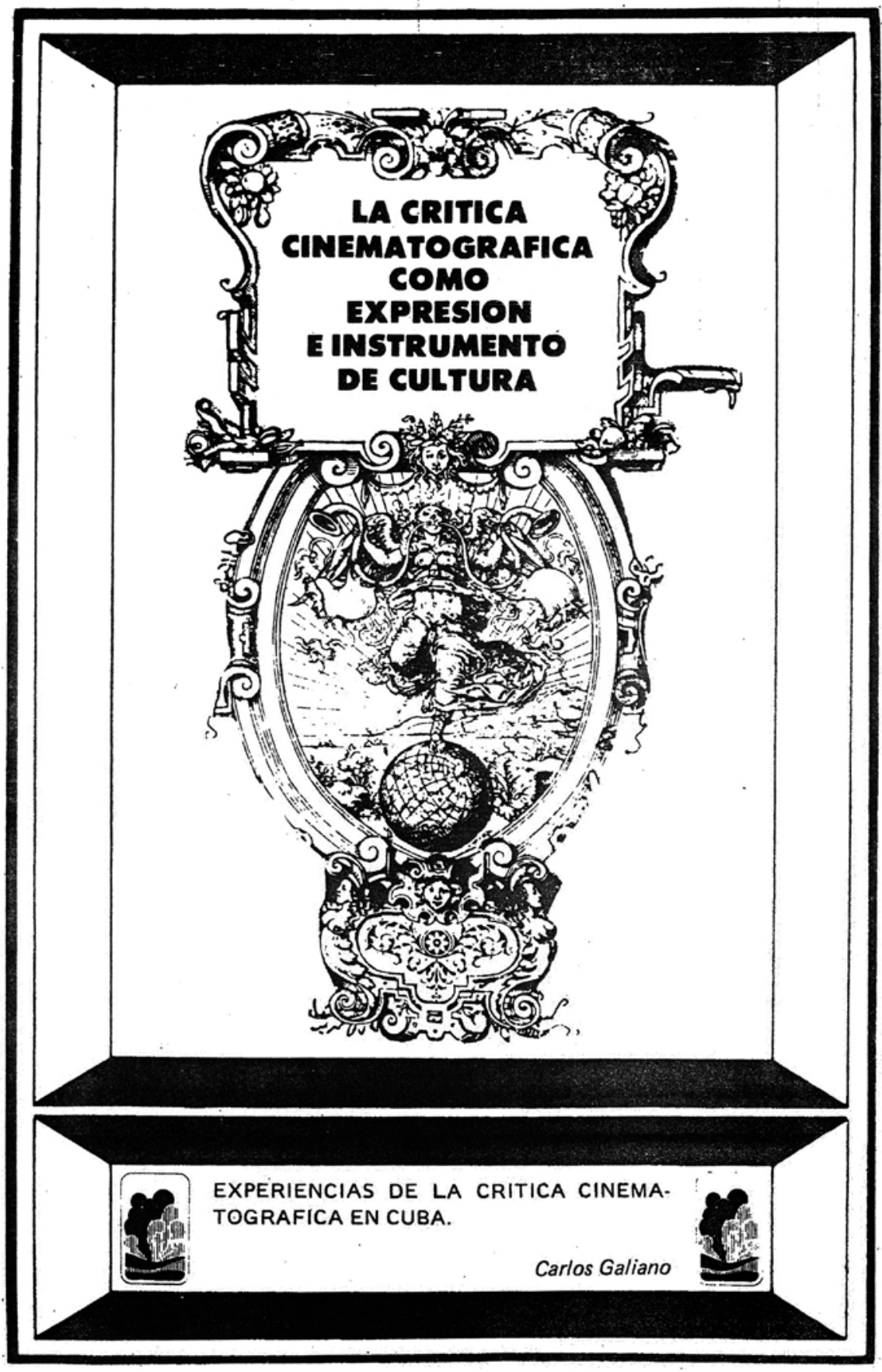

Ilustração, sem autor, para o artigo do crítico Carlos

Galiano, intitulado "Experiencias de la crítica cinematográfica en Cuba”, publicado na revista Cine Cubano, 1982, 101. 


\section{FORMAÇÃO, CAMPO E OCASO: REGISTROS DA CRÍTICA CINEMATOGRÁFICA NA AMÉRICA LATINA}

Em que consiste a crítica? Qual o seu papel em países específicos? Qual o seu estado nos dias de hoje em comparação a sua institucionalização nos anos de 1950/1960? Como se constitui a formação de um crítico? Que papel desempenha seu gosto pessoal? E como ele próprio se vê perante um suposto ocaso, tanto de seu meio quanto de seu objeto - o cinema? Estas e outras questões aqui tratadas à luz de discursos de críticos argentinos, cubanos e mexicanos compreendem o escopo de uma investigação iniciada em 2006. ${ }^{1}$ Com base em relatos e memórias, naquele ano dei início a uma espécie de cartografia sociológica da crítica cinematográfica na América Latina considerando quatro países em questão. Para tanto, somei ao trabalho entrevistas com críticos brasileiros, ainda em processo de finalização. ${ }^{2}$

Longe de tentar definir "a" crítica, tal qual uma entidade uniforme, tentarei, neste artigo, empreender uma breve sociologia da crítica, mapeando os campos de determinada conjuntura geográfica. Noto, desde logo, que, assim como o cinema, a crítica cinematográfica não se definiria pelo artigo que a precede. Em outras palavras, a impossibilidade de significação precisa para "o" cinema seria a mesma para "a" crítica, uma vez que ambos se constituem de inúmeras formas, narrações, discursos, lugares, tempos, subjetividades. Não obstante, não seria tal indefinição congênita a nos impedir de escrever sobre tais objetos, bastando-nos mapear o campo de interesse e o foco de ação. Deste modo, entre a sociologia da cultura e os estudos de cine- 
ma, proponho discutir alguns fundamentos do que se entende por crítica cinematográfica.

Quanto aos campos em que a pesquisa se inscreve, noto que para a sociologia da cultura, pode-se dizer, o cinema ainda é tido como objeto, de certa forma, à margem. Basta observarmos a definição de Nathalie Heinich em seu livro intitulado A sociologia da arte (2008), em que a socióloga francesa distingue "sociologia da arte" do termo "sociologia da cultura", não obstante sua ampla associação. Heinich considera este último termo essencialmente polissêmico, principalmente por não selecionar o objeto da sociologia por ela tratada, no caso as artes em seu sentido restrito de patrimônio. Tal especificação compreende as artes plásticas, a literatura e a música, e deixa de fora artes do espetáculo, cinema, mídia, artesanato e artes aplicadas. Curioso notar que tal acepção converge com a citada por Lucio Mendieta y Nunez, em texto intitulado Sociologia da arte, publicado na segunda série organizada por Gilberto Velho (1967), em que, das diversas formas de classificação da arte, "uma primeira divisão as distingue em artes maiores ou belas-artes e artes menores ou industriais; ter-se-ia que acrescentar as artes populares ou folclóricas, porém quando se fala de arte entende-se que se refere às belas-artes: música, dança, pintura, arquitetura, escultura, literatura" (Mendieta y Nunez, 1967: 61).

Já em relação aos estudos de cinema, é possível notar que não são poucos os trabalhos pautados em análises fílmicas a fundamentarem teorias que já compuseram ou estão a compor tradições de pensamento. Contudo, se olharmos para o lado da crítica, verificaremos uma incipiência temática, sobretudo quando buscamos pesquisas acerca da recepção e de assuntos afins depreciados, de certo modo, pela instituição acadêmica mais ocupada com investigações orientadas à produção e decodificação de filmes.

É justamente deste entre-lugar que busco compreender uma forma específica e localizada de recepção com base numa etnografia da crítica, cujas fontes primárias são os próprios críticos em questão.

\section{CRÍTICA E CRISE: MÉXICO E ARGENTINA}

Em primeiro lugar, aponto a uma tendência dicotômica revelada nas entrevistas. Por um lado, observa-se no México, na Argentina e em Cuba, assim como no Brasil, que, contrariamente às críticas literária e de arte, não são muitos os escritos teóricos e acadêmicos sobre crítica cinematográfica, ainda que esse campo tenha crescido nos últimos anos. Por outro lado, são inúmeras as discussões lato sensu que sugerem uma crise, ou até mesmo um "fim" da crítica. Ou seja, ainda principiante de um lado, do outro, a crítica de cinema, por intermédio de seus porta-vozes, já propaga seu suposto ocaso. Desse 
paradoxo é imperativo que se atente às dualidades distintivas apontadas em alguns discursos. Se tomarmos em consideração as múltiplas opiniões dos críticos entrevistados, não chegaremos a uma conclusão precisa sobre sua função, tampouco sobre sua suposta consumação. Poderemos, isto sim, apreender alguns dos motivos para ideias positivas e fatalistas dos agentes do campo, compreendendo suas lutas e interlocuções.

A começar pelo México, creio oportuno descrever relatos de três personagens influentes: Nelson Carro, Leonardo García Tsao e Jorge Ayala Blanco. ${ }^{3}$ Atuando como crítico no México desde 1977, o uruguaio Nelson Carro, formado em engenharia química, faz parte de um tempo em que não havia formação ou especialização para o ofício que acabou por escolher. Até a época da entrevista, escrevia para o semanário Tiempo Libre, um guia da Cidade do México com várias seções culturais, de lazer e entretenimento. Tornou-se crítico pela cinefilia. Não somente por conta da proliferação de cursos e escolas de cinema, para ele, seu campo não tem diminuído, muito ao contrário, tem se difundido amplamente, ocupando espaços diversificados. Entretanto, sua qualidade teria enfraquecido.

Ao analisar não somente o campo mexicano, Carro observa um novo modus operandi da recepção em países latino-americanos ao abrirem mão de espaços próprios para o cultivo da cinefilia (cinematecas e cineclubes, por exemplo), que estabeleciam claras diferenciações com a produção industrial. Apesar do esmaecimento cada vez mais significativo daqueles espaços, em sua visão ainda não seria possível falar em extinção da crítica, uma vez que ela - "mal ou bem" - continua a orientar o espectador. Ou seja, mesmo sem a força de outrora, a instituição crítica ainda seria capaz de fornecer ao espectador elementos sem os quais sua recepção seria limitada.

Parte de uma geração formada diretamente pelo método autoral, Carro atenta ao fato de meios como a Internet não contarem com sistemas de avaliação, critérios ou regras relativos à escritura, cabendo ao espectador-leitor o discernimento sobre o que serviria ou não à sua reflexão. Para ele, um leitor com formação e hábitos muito distintos dos do crítico dificilmente criaria interlocução com seu texto. A crítica seria mais bem aproveitada como ferramenta quando existisse uma afinidade de gosto. E aqui o verbo afinar pode e deve ser empregado em duplo sentido: de semelhança e harmonia do gosto, e de torná-lo mais fino, aprimorado.

Um pouco mais pessimista que Nelson Carro, o mexicano Leonardo García Tsao, que escreve para o maior jornal mexicano de esquerda, La Jornada, também exerce a função de crítico há trinta anos. A possível extinção da crítica no México, para ele, estaria vinculada tanto à sua profissão, cada vez mais irrelevante, quanto ao fenômeno da Internet, que "gera um diálogo amador mais imediato e acessível às massas". O interessante a notar na reflexão de Tsao é que a nova postura em relação à crítica estaria diretamente 
relacionada ao próprio ato da recepção, já que, atualmente, "não mais se assiste a filmes como há trinta/quarenta anos", sendo a postura do receptor, em nossos dias, "sensorial, urgente e entretenida". Para Leonardo Tsao, contrariamente aos anos de 1960 e 1970, em que se assistia a filmes europeus, asiáticos e latino-americanos, numa época em que refletiam fundamentos ideológicos, no "vazio cultural" atual o público se "satisfaz, apaticamente, com a indústria”.

Levando ao paroxismo a visão pessimista deste último crítico, Jorge Ayala Blanco, que escreve para o jornal El Financiero, fundado em 1981 e dedicado principalmente ao jornalismo econômico, acredita que a crítica mexicana não corre perigo de extinção, uma vez que já teria sido extinta. Engenheiro químico, Ayala Blanco se situa num campo oposto ao dos dois acima tratados, o que os leva a embates por vezes pessoais. Como outros críticos, ${ }^{4}$ ele foi discípulo de Emílio García Riera (cuja importância equivale a Paulo Emílio Salles Gomes, no Brasil), imigrante espanhol, como muitos intelectuais foragidos para o México durante a Guerra Civil, crítico pioneiro e um dos mais importantes do país na década de 1960. García Riera e outros de sua geração foram influenciados pela política dos autores francesa, fundando, em 1961, a revista Nuevo Cine, o primeiro veículo mexicano de crítica formal.

Em determinado momento, Ayala Blanco rompe com García Riera, juntando novos discípulos em campo oposto. Dos seguidores do método de autor implementado por Riera, muitos abandonaram o ofício da crítica, e os únicos que ainda escrevem com periodicidade são Nelson Carro e Leonardo García Tsao. Apesar de persistirem numa luta de campos definidos e opostos, o grupo de García Riera e o desconstrutivista, que tem como representante Jorge Ayala Blanco, não contam com veículos a delimitar seus espaços. Suas posições dispersas em diversos meios dificultam qualquer embate crítico mais legitimado. Como indica Tsao, "a situação cultural no país está tão pobre que não existe revista, nem de um lado nem de outro". Em irônica concordância, Ayala Blanco sustenta que atualmente o que mais se produz no México "não é crítica, mas sinopses e promoções de filmes comerciais".

Ao marcar seu posicionamento "anticinema de autor", Ayala Blanco se autointitula "crítico de filmes, e não de cineastas". A ele não interessam métodos que versem sobre o autor ou sobre a função social do filme, utilizados por agentes opositores, "que escrevem como se estivessem conversando, em vez de sobrecarregarem a crítica de ideias a partir de um discurso autônomo". A prática crítica, em sua concepção, deve ser reservada ao método barthesiano de desconstrução do discurso fílmico. O puro julgamento de um filme não entraria na categoria de análise escritural mais aplicada por refletir "uma atitude conformista". "A verdadeira crítica das instituições e linguagens", afirma, consiste em "desmontar, desconstruir uma narrativa". Ao declarar que escreve para um público/leitor "inteligente", Blanco sustenta que o texto crítico nunca 
deve imprimir um tom informal ou coloquial, uma vez que tal "facilismo" seria a "causa do empobrecimento da cultura nos países latino-americanos".

O empobrecimento da cultura cinefílica, a escassez de espaço para a crítica e sua falta de renovação são problemas constatados não somente pelos críticos mexicanos, mas também pelos argentinos, que alternam, assim como seus pares hermanos, pontos de vista pessimistas e otimistas em relação ao ocaso de sua função. ${ }^{5}$ Ao concordarem com a ideia de que a nova cinefilia tem definitivamente adotado uma forma de recepção cinematográfica distinta da tradicional, os argentinos baseiam-se em dois princípios essenciais: a nova escritura não mais estaria pautada num tempo histórico cinematográfico; a instituição cinema teria perdido sua unidade lógica com a proliferação de outras formas de audiovisual.

Eduardo Antín, fundador da revista El Amante ${ }^{6}$ no início da década de 1990, e atualmente crítico independente, afirma que o cinema, além de assimilar linguagens de outras culturas audiovisuais, desvinculou-se de seu formato clássico e específico, podendo ser visto na televisão, no museu, na universidade, no computador. Este fato teria sido responsável por seu relativo ganho de importância se comparado ao que tinha há cinquenta anos, quando do nascimento da crítica moderna. Entretanto, sua concepção conteudista estaria diminuindo gradualmente, uma vez que o consumo formalista do cinema se equipararia a outros bens e espetáculos. Para ele, simultaneamente à perda de certa aura cinematográfica, a nova recepção envolveria uma anulação da esperança estética, política e social antes existente. O espalhamento da função do cinema ocasionaria uma dispersão do papel da crítica, que busca, sem encontrar, novos pontos de diálogo com a obra, com os meios e com o público. Desta forma, ela acabaria perdendo espaço para o jornalismo cinematográfico, resumindo-se a notas promocionais, entrevistas e matérias afins.

Na contramão desse movimento, Antín aponta para outro fenômeno: enquanto grandes críticos, como o francês Serge Daney, sempre tentaram conciliar no texto elementos da "'alta cultura' e das ciências sociais com o 'gosto ingênuo' e com a concepção do cinema como espetáculo popular, ou seja, como fenômeno de massa, os novos críticos tendem a uma leitura mais compartimentada". Dessa forma, o cruzamento clássico anterior teria cedido lugar a uma sorte de especialização implementada por uma disciplinarização acadêmica do cinema, o que representaria uma mudança histórica importante. Professor de matemática, o crítico vê com estranhamento o fenômeno vivenciado pela revista que fundou junto com amigos - "simplesmente para traduzir na escritura o prazer da fruição cinematográfica” - quando ela passou a funcionar como espaço para promoção de cursos de crítica. Diferentemente de sua experiência diletante, já que "acabou virando crítico sem querer, de forma orgânica”, Antín verificou no próprio meio por 
ele criado uma outra forma de desenvolvimento da profissão - academicista, disciplinarizada.

Da mesma geração deste último crítico, Luciano Monteagudo, que atualmente escreve para o jornal Página 12,7 entrou na crítica pelo cineclubismo em meados dos anos 1970, "numa época em que ainda não existia vídeo". Nesse mesmo período, em março de 1976, quando do Golpe Militar, o crítico ingressou no curso de letras da Universidade de Buenos Aires, sem chegar a concluir, pois "as disciplinas humanas foram as que mais sofreram e, dessa forma, o contexto não ajudou para avançar na carreira”. De sua experiência com a escritura cinematográfica, Monteagudo constata que a indústria tem "obturado e expulsado o crítico dos meios institucionalizados - antigamente, espaços de poder, mas hoje de desinteresse tanto para o crítico quanto para o leitor". Neste contexto, um lugar ainda garantido ao crítico seria o da curadoria e o da programação de festivais e ciclos independentes, em que há a possibilidade de intervenção, de proposição e de diálogo com o espectador-leitor. Monteagudo afirma que o “'bom cinema' e a 'arte autêntica' pertencem a espaços de resistência”. A seu ver, enquanto houver necessidade deste tipo de expressão, haverá igualmente uma "boa crítica" que responda a estes materiais, não de maneira indulgente ou paternalista, mas de modo a resistir por meio da escritura.

Representando uma corrente mais academicista, Eduardo Russo, professor da Universidad Nacional de La Plata, suspeita da tese de um predomínio de profissionais com vínculos com grandes grupos midiáticos. Para ele, seria errôneo o entendimento de que a função clássica do jornalismo, "tal como propagada no século XVII e fortalecida no século XX, por meio de ideias como a de quarto poder, teria perdido lugar para uma comunicação promovida por corporações". Esse tipo de crítico ligado à função de árbitro midiático estaria asfixiado, enquanto a crítica alternativa estaria longe de se extinguir. Russo indica que a instituição ressurge de forma diferente nos novos meios - websites e blogs - "nos quais há um desejo crítico poderoso que torna possível praticar a discussão que nasce dos filmes, prolongando-os em outros suportes". De certa maneira, essas formas de criação crítica dariam continuidade à lógica diletante dos "primeiros críticos" ou dos "críticos modernos", que discutiam filmes de forma apaixonada, passando a entender o cinema a partir de livres fruições. Tal julgamento dá a entender que, embora tenha havido uma transferência de um status diletante para uma condição burocratizada e profissionalizada do campo, ainda seria possível escrever crítica e pensar cinema à moda antiga. Assim, novos veículos, mantendo certa tradição conceitual e metodológica, apontariam para um futuro estimulante ao implementarem discursos singulares e autônomos. Ao diferenciar a recepção quantitativa da qualitativa, Russo questiona o valor simbólico da escritura, acreditando que "em meios massivos como a Internet, por 
exemplo, é possível estabelecer conexões mais comprometidas do que em meios mais clássicos".

Nesse âmbito, uma outra situação da qual se deve desconfiar é a "defesa da crítica a filmes nacionais". De acordo com Eduardo Russo e outros críticos argentinos, especialmente devido à ideologia nacionalista implementada pela ditadura, era (e ainda é) comum a crítica argentina aplicar um padrão de valoração distinto aos filmes nacionais e aos estrangeiros. Na atitude de ampla defesa pelo nacional, o que menos importa na avaliação da película é sua qualidade. O que preocupa Russo ao pensar tal postura é um exaltamento de uma política de exportação. Em outras palavras, o perigo de proteção conferida ao cinema argentino seria sua valorização como entidade monolítica, criando-se um padrão de arte como produto de exportação "como se fosse uma caixa de vinho ou de alimentos em conserva". Esse entendimento de positivação irrestrita do que é "nosso" iria de encontro à própria concepção de crítica, cuja função, para Russo, estaria em desenquadrar e expandir a forma de pensar.

\section{TERCEIRA ORDEM COMPARATIVA: O CASO CUBANO}

A pertinência em estabelecer um terceiro eixo comparativo está em ampliar o entendimento/mapeamento do campo crítico atentando a consensos e dissensos discursivos em perspectiva mais continental. De pensamentos clássicos a meios alternativos, veremos que críticos cubanos assumem posições menos pessimistas que as dos mexicanos, e mais otimistas que as dos argentinos. Deles, trago dois exemplos distintos: as considerações de Joel del Río, que trabalha para veículos institucionalizados, e de Dean Luis Reyes, crítico independente que elabora suas análises fora do meio. ${ }^{8}$

Formado em geografia, Del Río escreve para o jornal Juventud Rebelde, para a revista Cine Cubano e para sítios eletrônicos como o da Escuela Internacional de Cine y Televisión (EICTV). ${ }^{9}$ Quando perguntado sobre o possível fim de sua profissão, relativiza tal teoria, definindo seus diversos papéis. Para ele, a crítica massiva - transmitida em jornais, Internet, televisão ou rádio - não tende a desaparecer, muito ao contrário. Por outro lado, a crítica ensaísta, pautada na política dos autores e veiculada em revistas especializadas, pode vir a ter um destino um pouco mais conturbado, o que não significa que será extinta, na medida em que "sempre haverá grupos e cinéfilos interessados nesse tipo de ensaio e em sua relação com o cinema”. A crítica, em suas múltiplas variantes, só desapareceria "caso desaparecesse o desejo de conhecimento dos seres humanos". Entusiasmado com a carreira que escolheu, Del Río afirma existirem quase tantas formas de crítica quanto de cinemas. Neste contexto, é interessante notar que o cubano não faz distinção entre cinema 
comercial e cinema de arte. Mesmo quando trata dos diferentes tipos de crítica, não se baseia em princípios distintivos. Para ele, tal posicionamento põe em xeque determinadas regras ou preceitos de gosto, fazendo com que a profundidade da escrita e suas opções metodológicas sejam incutidas a priori pela obra em si, e não pela subjetividade do próprio crítico.

Ao se intitular um pertencente à "terceira geração de críticos da revolução", descreve o campo cubano tomando como base seus predecessores, que fizeram parte do que chama de "crítica pedagógica". Joel conta que a década de 1960 em Cuba foi de grande efervescência cultural, tendo como ícones cineastas/documentaristas como Santiago Alvarez e filmes como Memórias do subdesenvolvimento, de Tomás Gutiérrez Alea, que por si só teriam sido tão produtivos e críticos que "não precisavam de críticas" - estas últimas, por sua vez, também geradoras de debates polêmicos. Por motivos econômicos e políticos, o "mundo bipolar" dos anos 1970 testemunhara um maior recolhimento não apenas da crítica como também do cinema cubano, na medida em que efeitos da ditadura se refletiram diretamente no universo cinematográfico. Em decorrência da "sovietização" do país, teriam diminuído espaços de reflexão, de crítica e de manifestações artísticas. Em 1990, quando começou a trabalhar com crítica de cinema, Joel del Río percebeu um alargamento do campo, que passou a abarcar vários tipos de ideias e debates. A seu ver, atualmente existem críticos que praticam uma escritura mais analítica e literária, críticos mais promocionais e aqueles que ainda seguem o modelo pautado no realismo socialista. Isto quer dizer que "de lá para cá a crítica cubana tornou-se mais pluralizada".

Colega de Del Río da EICTV, Dean Luis Reyes também compartilha da visão mais pluralista. Para ele, em seu país, "o velho modo de fazer crítica corre perigo de extinção, dada a escassez de recursos necessários para compreender novas formas cada vez mais contaminadas de linguagens cinematográficas". Assim, a contaminação do cinema contemporâneo refletiria a dissolução de antigas hierarquias que feriam a concepção simbólica do cinema. Esse movimento seria positivo na medida em que implicaria o desaparecimento de "dinossauros", que seguiam paradigmas estruturantes, em oposição ao surgimento de "novas formas de vida que abrem múltiplos caminhos para se pensar o cinema por meio de teorias - como os estudos culturais, pós-coloniais, perspectivas semiológicas, entre outros". Reyes aponta o caminho da crítica em direção a um conhecimento renascentista, não mais limitado a hierarquias e paradigmas absolutos. Deste modo, "em oposição à cinefilia clássica, que se dedicava a um conhecimento ilustrado e elitista, a crítica renascentista atual tem se tornado cada vez mais democrática". Tal arranjo imaginado pelo crítico não seria de todo positivo uma vez que contaria com dificuldades intrínsecas ao campo a irem à seguinte direção: ao se institucionalizar, a crítica passa a estruturar modelos que negam a possibi- 
Ilustração de capa da revista Cine Cubano, 1972, n. 73/74/75. Cine Cubano é uma das mais importantes referências latinoamericanas no campo cinematográfico, tendo concentrado todo um debate acerca do movimento denominado Nuevo Cine Latinoamericano.

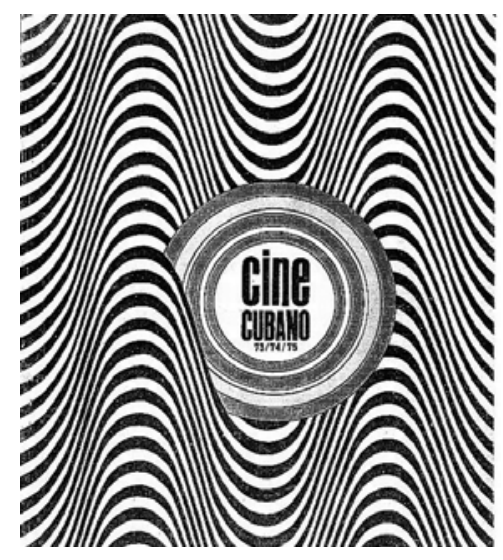

lidade de emergência de discursos plurais e móveis, com potencial ampliação do debate. Para Dean, em Cuba haveria uma "economia simbólica que se reproduz muitas vezes com a contradição entre o discurso e a prática". Apesar do desejo de pluralizar a crítica, discursos diferentes ainda soam raros em decorrência de um pensamento que ainda vê vozes dissidentes de modo ameaçador.

Seja pautada por modelos estruturados ou por tendências mais fluidas, a crítica - definida por Reyes como um "discurso de poder, muitas vezes visto como parasitário, por vir depois da obra que, contudo, clarifica a relação entre intenção e resultado, a partir da qual se constrói um processo de conhecimento da própria realidade" - se estabelece a partir da racionalização do sensório, da transformação do sentimento em conhecimento racional. Tal procedimento geraria a essência do fazer crítico. Para ele, independentemente do modelo - "narratológico, impressionista, desconstrutivista, semiótico etc." - a atividade crítica pode ser descrita como um exercício de prazer. O perigo dessa concepção "fenomênica", no entanto, seria de "o crítico se deixar levar por opiniões, escapando de critério fundamentado em análise mais rigorosa, onde estaria sua habilidade e virtuosismo". Tal análise deveria pautar-se por uma contextualização sincrônica e diacrônica da obra, de forma a entendê-la em sua historicidade e complexidade, para que ela própria não se esgote.

\section{OUTROS SIGNIFICADOS DA CRÍTICA: VELHOS E NOVOS APONTAMENTOS}

Dos entendimentos de crítica aqui traçados é possível mapear dois principais tipos formadores de gerações constitutivas dos campos nos países abordados. A começar pelos agentes "ilustrados" da década de 1960, que instituíram o conceito de autor, vemos que não se formaram em cursos, mas em cineclubes. A consciência de pertencerem a um grupo social valorizado apoiava-se na ideia de estar a serviço de um projeto criador. O controle e a articulação dos agentes garantiam regras e práticas que se legitimavam pelo propósito de dever dar suporte a determinado autor ou cinematografia. Essa ideia e a política por ela inspirada asseguravam um 
campo e, ao mesmo tempo, conferiam seu prestígio. No entanto, a partir do momento em que sofre transformações, o status do crítico, como parte de um grupo supostamente qualificado, passa a ocupar um espaço indeterminado, a meio caminho entre uma ilustração atuante e uma "contraesfera pública desejável, mas inexistente" (Eagleton, 1991: 104).

Não obstante a produção especializada e restrita, a crítica cinematográfica experimenta um processo de democratização, ampliando-se pelo advento de novos espaços, como os meios eletrônicos, por exemplo. E aqui se encontra o segundo tipo descrito: os críticos das décadas de 1980 e 1990 que aprenderam lendo os trabalhos da geração anterior e se tornaram professores especializados de novos cursos de crítica e cinema. Estes últimos expressam opiniões diversas, tanto as que enfatizam o risco do hipotético fim da crítica, não obstante a sua amplitude em novos meios contemporâneos, quanto as que veem a pluralidade com otimismo, apontando para a riqueza da descentralização de padrões institucionalizados.

As várias tipificações e definições relativas à instituição crítica se tornam ainda mais explícitas se verificarmos outros apontamentos, rumos e posturas indicados por pensadores e profissionais. Em meados da década de 1990, o crítico brasileiro José Carlos Avellar já atentava para certo deslocamento da prática escritural ao sugerir que "talvez o desafio que o cinema agora propõe à crítica se encontre na aparente desnecessidade da crítica. Ela já não integra o espaço cinematográfico, ou continua parte dele em outra forma, latente, ainda não revelada de todo" (Avellar, 1996: 42-46). Ao considerar que o trabalho do crítico é "canalizar a consciência do espectador para a imagem em sua expressão simbólica; não lhe dizer qual significado tem o filme, mas mobilizar sua imaginação e inteligência", Michael Chanan, teórico inglês dedicado ao cinema latino-americano, reconhece novas condições a implicarem mudanças na forma da atividade crítica. Com relação a estas últimas, ressalta fenômenos como os de "a crítica formal-estética ter deixado de ser importante, ou começado a ocupar um segundo plano, ou encontrado seu lugar nas escolas de cinema" (Chanan, s/d: 75-78). Ao valorizar o papel do leitor na relação comunicacional, Roberto Smith, vice-presidente do Instituto Cubano del Arte e Indústria Cinematográficos (ICAIC), diagnostica que a crítica deveria conhecer características do público ao qual se dirige, por intermédio de ferramentas das ciências sociais contemporâneas, que "romperam com esquemas que consideravam o espectador como leitor homogêneo, passivo e indefeso ou com uma possibilidade de ação mecanicamente entendida". Nesse sentido, "a crítica deve estar consciente dessa diversidade, adequando os meios que utiliza à medida de suas aspirações" (Smith, s/d: 84-87).

Ao mesmo tempo prática escritural e exercício de interpretação, e construída em suportes e regras distintos dos de seu objeto, a crítica cinemato- 


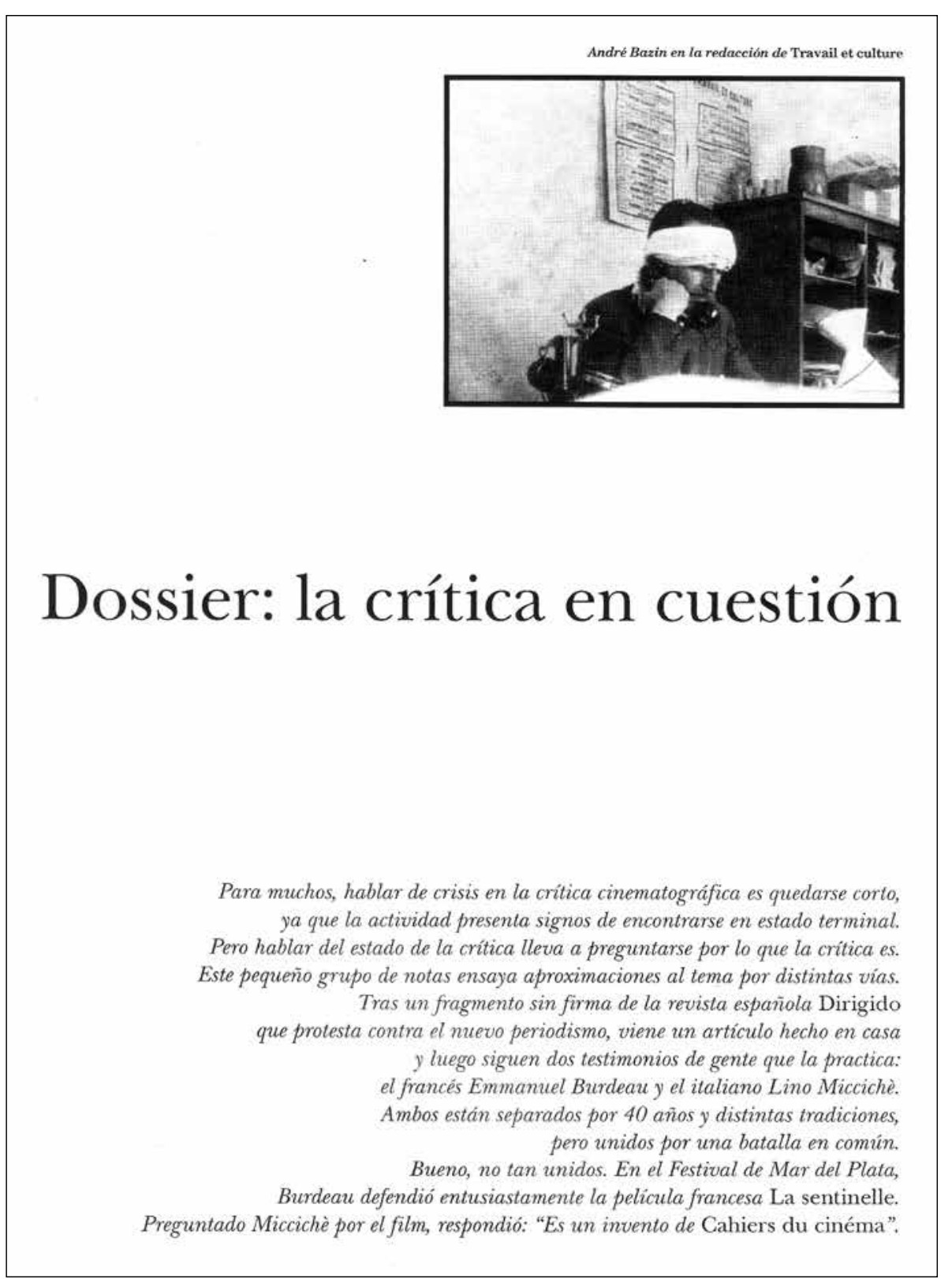

Dossier: la critica en cuestión faz parte do número 61, ano VI, março de 1997, da revista argentina El Amante - Cine. Do Dossiê consta artigo de Eduardo Antín (Quintín), que foi um dos fundadores da revista, criada no ano de 1991, com periodicidade mensal. Uma de suas características foi instituir o recurso linguístico da primeira pessoa, até então raro nos textos críticos. 
gráfica pode ser entendida como habilidade linguística reinventora de imagens em palavras, tradutora verbal de um estado sensório e mental por excelência. Em adaptação às palavras de Roland Barthes "o mundo existe, o cineasta fala, eis o cinema", a crítica existiria menos por conta do mundo diretamente do que por suas imagens, representando "o discurso de um outro", a saber, "o discurso sobre um discurso; uma linguagem segunda ou metalinguagem, que se exerce sobre uma linguagem primeira (ou linguagem-objeto)" (Barthes, 2007: 160, grifos do autor). Em conformidade com o entendimento barthesiano, Jean-Claude Bernardet faz referência a um paralelismo entre discurso crítico e obra fílmica, em que o primeiro não se identifica com a segunda, pelo contrário, entre ambos haveria um "jogo de aproximações e distanciamentos" (ver Bernardet, 1986). O objeto filme, desse modo, não estaria isolado à tela, mas encontraria uma forma de ser re-narrado e reinventado em discurso poderoso.

Na construção de cânones, a instituição crítica deveria constituir-se de formas mais complexas, não se propondo a descobrir verdades, mas, sim, validades em sistemas de signos específicos. Neste sentido, entendo ser necessária uma configuração mais pluralista do pensar cinematográfico em relação aos paradigmas da recepção. Diversificar a crítica, incentivar a disseminação de seus sentidos e ampliar suas articulações e espaços são pressupostos que sugerem um bom início para pensarmos não apenas as novas condições de recepção, como seu próprio estudo sociológico.

Eliska Altmann é professora adjunta da Universidade Federal Rural do Rio de Janeiro (UFRRJ), no Departamento de Ciências Sociais e no Programa de Pós-Graduação em Ciências Sociais (PPGCS). Autora do livro O Brasil imaginado na América Latina - a crítica de filmes de Glauber Rocha e Walter Salles (2010). Idealizadora do portal eletrônico "CineCríticos" (www.cinecriticos.com.br). 


\section{NOTAS}

1 Como amostra de pesquisa mais ampla, citarei alguns trechos de entrevistas realizadas em cada país. Ao todo, foram entrevistados os seguintes críticos: da Argentina: Eduardo Antín, Eduardo A. Russo, Gustavo Noriega, Javier Porta Fouz, Jorge García, Luciano Monteagudo, Sergio Wolf e Silvia Schwarzböck. De Cuba: Alberto Ramos Ruiz, Antonio Mazón, Dean Luis Reyes, Joel del Río, Luciano Castillo, Maria Caridad e Mario Naito. Do México: Carlos Bonfil, Fernanda Solórzano, Javier Betancourt, Jorge Ayala Blanco, José de la Colina, Leonardo García Tsao, Nelson Carro, Rafael Aviña e Tomás Perez Turrent.

2 Os críticos brasileiros entrevistados até o momento foram: Andrea Ormond, Carlos Alberto Mattos, Cléber Eduardo, Daniel Caetano, Eduardo Valente, Francis Vogner dos Reis, Ismail Xavier, Jean-Claude Bernardet, José Carlos Avellar, Marcelo Janot, Marcelo Miranda, Marcus Mello, Pedro Butcher, Rodrigo Fonseca, Ruy Gardnier. Seus relatos, ainda não sistematizados, não fazem parte da presente análise.

3 As três entrevistas foram realizadas na Cidade do México em 26, 28 e 31 de julho de 2006.

4 Além dos dois citados, os também entrevistados Tomás Perez Turrent e José de la Colina, por exemplo.

5 Os críticos argentinos foram entrevistados entre dezembro de 2006 e janeiro de 2007.

6 De periodicidade mensal, a revista instituiu o recurso linguístico da primeira pessoa, raro até então. Embora dedicada exclusivamente ao cinema (e não a outras formas de entretenimento, espetáculos e lazer), El Amante tem um público amplo e diverso, e seus textos fogem do academicismo, valorizando uma cinefilia informal.

7 Fundado nos anos 1980 e com viés de esquerda, Página 12 é hoje um dos diários mais influentes da Argentina, ainda que sua linha editorial tenha sido alterada desde que foi parcialmente adquirido pelo grupo Clarín, no fim dos anos 1990.

8 Os críticos cubanos foram entrevistados em outubro de 2006.

9 Com o subtítulo Diário da juventude cubana, o Juventud Rebelde, segundo periódico de maior tiragem do país, foi fundado por Fidel Castro, em outubro de 1965, no contex- 
to do V Aniversario de la Integración del Movimiento Juvenil Cubano. Depois de contar com edições extras e tiragens nacionais, em 1997, o jornal ganhou versão eletrônica. Cine cubano, uma das mais tradicionais referências latino-americanas no campo cinematográfico, concentrou um debate acerca do "movimento" denominado Nuevo Cine Latinoamericano. Criada como veículo do ICAIC e fundada em 1960, logo após a revolução cubana, a revista pode ser considerada uma espécie de Cahiers du Cinéma latino-americano.

\section{REFERÊNCIAS BIBLIOGRÁFICAS}

Avellar, José Carlos. (1996). A arte da crítica, crítica da arte. Nossa América - Revista do Memorial da América Latina, 1, p. 42-46.

Barthes, Roland. (2007). Crítica e verdade. São Paulo: Perspectiva.

Bernadet, Jean-Claude. (1986). O cinema segundo a crítica paulista. São Paulo: Nova Stella.

Chanan, Michael. (s/d). El cine como realidad del outro. La situación de la crítica del NCLA en Inglaterra. Cine Cubano, La Habana, 101, p. 75-78.

Eagleton, Terry. (1991). A função da crítica. São Paulo: Martins Fontes.

Heinich, Nathalie. (2008). A sociologia da arte. Bauru, SP: Edusc.

Mendieta y Nunez, Lucio. (1967). Sociologia da arte. In: Velho, Gilberto (org.). Sociologia da arte. Rio de Janeiro: Zahar (Série II), p. 54-72. 
Palavras-chave

Crítica; Cinema;

América Latina;

Teorias da recepção; Sociologia da cultura.
Keywords

Criticism; Cinema;

Latin America;

Theories of reception;

Sociology of culture.
FORMAÇÃO, CAMPO E OCASO: REGISTROS DA CRÍTICA CINEMATOGRÁFICA NA AMÉRICA LATINA

\section{Resumo}

No contexto dos estudos da recepção, o artigo traz resultados de uma pesquisa sobre crítica cinematográfica na América Latina por intermédio de pressupostos sociológicos. Formação, campo e um suposto ocaso da função da crítica são elementos-chave para a discussão dos personagens em questão. Assim, com base em entrevistas com críticos da Argentina, de Cuba e do México, são discutidas questões do tipo: qual o papel específico da crítica nesses países? E qual o seu estado nos dias de hoje em comparação a sua institucionalização nos anos de 1950/1960? Apesar da dificuldade de se chegar a uma definição estrita sobre a instituição "crítica", busca-se 1) valorizar o debate sobre recepção de bens culturais, e 2) compreender certo circuito latino-americano nele inscrito.

\section{FORMATION, FIELD AND DECLINE: RECORDING FILM CRITICISM IN LATIN AMERICA}

\section{Abstract}

In the context of reception studies, this paper presents the results of a survey of film criticism in Latin America based on sociological assumptions. Formation, field and a supposed decline of the function of criticism are key elements for the discussion of the critics in question. Thus, based on interviews with critics of Argentina, Cuba and Mexico, this article addresses questions such as: what is the specific role of criticism in these countries? And what is their status today compared to its institutionalization in the years 1950/1960? Despite the difficulty of reaching a strict definition of the "critic" institution, we seek to 1) enhance the debate on reception of cultural goods, and 2) understand a Latin-American circuit inscribed on it. 